\title{
Danos mecânicos em sementes de feijão Vigna, causados pelas operações na unidade de beneficiamento ${ }^{1}$
}

Francisco de A. C. Almeida ${ }^{2}$, Acácio Figueiredo Neto ${ }^{3}$, Rubens F. da Costa ${ }^{4}$, Josivanda P. G. de Gouveia ${ }^{2} \&$ Maria E. C. de Oliveira ${ }^{3}$

1 Parte da Dissertação de Mestrado apresentada pelo segundo autor na UFCG
2 DEAg/UFCG. Av. Aprígio Veloso, 882, CEP 58109-970, Campina Grande, PB. Fone: (83) 310-1287. E-mail:
diassis@deag.ufcg.edu.br (Foto) e josi@deag.ufcg.edu.br
${ }^{3}$ Pós-graduado, UFCG. Fone: (83) 331-3439. E-mail: acaciofn@terra.com.br
${ }^{4}$ Pesquisador da EMEPA, CEP 58390-000, Alagoinha, PB. Fone: (83) 278-1243. E-mail: rubens56@uol.com.br

Protocolo 200 - 15/12/2003 - Aprovado em 17/8/2004

\begin{abstract}
Resumo: Depois da colheita e debulha, as sementes de feijão são encaminhadas à usina de beneficiamento, de onde, por elevadores, são conduzidas às máquinas de pré-limpeza, limpeza, separação e classificação, tratamento e embalagem, para posterior armazenamento experimentando durante este percurso, impacto promovidos pela movimentação dos elevadores e das máquinas. Objetivando-se contribuir com o programa de controle de qualidade de sementes de feijão produzidas principalmente no estado da Paraíba, estudaram-se os impactos mecânicos sofrido pelas sementes de duas variedades de feijão Vigna com dois teores de umidade $(13,5$ e 7,3\%) depois da colheita, debulha e da passagem pelas diferentes etapas na Empresa de Pesquisa Agropecuária da Paraíba, localizada em Alagoinha, PB. Os danos decorrentes dos impactos foram analisados visualmente, empregando-se um delineamento inteiramente casualizado em esquema fatorial $2 \times 2 \times 5$, submetendo-se as médias dos fatores quantitativos a regressão na análise da variância. As sementes com umidade de $7,3 \%$ da variedade Rabo de Tatu são mais susceptíveis à quebra pelos impactos no processo e, às injúrias, elevam-se com o aumento do número de passagem das sementes pelas diferentes etapas à qual estão sujeitas, demonstrando caráter cumulativo, indicando haver relação direta entre o número de choques e seus efeitos.
\end{abstract}

Palavras-chave: impactos, processamento, controle de qualidade

\section{Mechanical damages in Vigna bean seeds caused by the operations in the seed processing}

\begin{abstract}
After harvesting and threshing the seeds of beans are taken to a seed processing plant where from by elevator are taken to machines of pre-cleaning, cleaning, separation and classification, treatment and packing for posterior storage. During this course, impacts are promoted by the movement of elevators and machines. With the objective to contribute with quality control program of bean seeds mainly produced in the Paraíba State, the mechanical impacts undergone by seeds of two varieties of Vigna bean with two moisture contents (13.5 and 7.3\%) were studied after harvesting, threshing and passage through different stages at the Empresa de Pesquisa Agropecuária da Paraíba, located in Alagoinha, PB. Mechanical damages of impacts were statistically analysed, in a completely randomized experimental design in a $2 \times 2 \times 5$ factorial seheme, submitting the means of quatitative factors to regression in variance analysis. Seeds with moisture content of $7.3 \%$ of the variety 'Rabo de Tatu' were most susceptible to breakage by impacts caused during the processing and the injuries increased with the number of passages of seeds throngh different stages of processing to which seeds are subjected, showing accumulative character, indicating a direct relation between the number of shocks and their effects.
\end{abstract}

Key words: impacts, processing, quality control 


\section{INTRODUÇÃO}

No Brasil, a cultura do feijão é uma das mais importantes, não apenas por fazer parte, em boa proporção, da massa alimentar da população, mas, sobretudo por envolver uma grande área de produção cultivada, na sua maior parte, por pequenos agricultores, assim distribuídos: $77 \%$ de toda a produção de feijão proveniente do gênero Phaseolus e 23\% do gênero Vigna, em que a região Nordeste é a principal produtora, em termos de área plantada e produção, enquanto cerca de $60 \%$ de toda a produção são do gênero Vigna (Yokoyama et al., 2000).

Nos últimos dois anos a produção brasileira de feijão oscilou entre 2,7 e 3,08 milhões de toneladas (CONAB, 2003), tendo o estado da Paraíba participado com 12 e 56 mil toneladas, em uma área plantada de 30 e 160 mil hectares, respectivamente (Papes, 2002); no entanto, entre as grandes culturas como arroz, milho, soja e trigo, o feijão é a que apresenta as menores produções por unidade de área. Um dos principais fatores segundo os tecnologistas de sementes se refere a baixa utilização de sementes certificadas e, ou, fiscalizadas.

No estado da Paraíba, a grande maioria dos produtores de feijão e, praticamente, todos os pequenos produtores de Vigna, utilizam na semeadura a mesma semente destinada para a alimentação. A colheita consiste, normalmente, do arrancamento manual das plantas, secagem ao sol no terreiro e posterior batedura e, raramente, usam-se máquinas combinadas.

No processamento, tanto as sementes quanto os grãos são submetidos à debulha mecânica ou manual, as primeiras com o auxílio de máquinas pneumáticas atreladas ao trator, e as segundas com uso de varas na batedura das plantas espalhadas nos terreiros, completando-se o processo com a abanação e ensacamento manuais. No caso específico de sementes, depois do ensacamento elas são encaminhadas à Unidade de Beneficiamento de Sementes, (UBS), em que, por meio de elevadores, são conduzidas às máquinas de prélimpeza, limpeza, separação e classificação, tratamento e embalagem.

A semente de feijão possui tegumento delicado e seu embrião ocupa posição lateral e superficial, pelo que está mais sujeita às avarias mecânicas durante as etapas impostas pela UBS, que outras sementes sem essas características morfológicas.

Segundo Andrade et al. (1999) a injúria mecânica e misturas de variedades são apontadas pelos tecnologistas como uns dos mais sérios problemas da produção de sementes por se constituírem em uma questão praticamente inevitável, em virtude das principais fontes desse dano se encontrarem em todas as etapas do processo produtivo (colheita, beneficiamento, armazenamento e transporte). Essas danificações são provocadas por impactos nas sementes, em virtude de vários fatores, como tensão aplicada na quebra das sementes, umidade, dureza e características genotípicas do produto, influência e susceptibilidade à quebra, a qual se refere ao potencial de fragmentação do produto quando este é submetido a uma força de impacto durante o beneficiamento ou transporte (Gunasekaran \& Muthukumaratpan, 1993) em que as sementes passam por elevadores, transportadores e máquinas, sofrendo quedas que causam lesões ou danos no tegumento, endosperma e embrião (Martins Netto et al., 1999).

Essas operações complementam as atividades de campo e preparam a semente para o armazenamento até a comercialização e futuro plantio da safra seguinte; portanto, em apoio aos programas de controle de qualidade de sementes que têm, como objetivo básico, identificar problemas e suas possíveis causas, visando ao controle de todas as etapas da produção de sementes que assegurem a comercialização do produto com elevada qualidade genética, física, fisiológica e sanitária, fazse necessário estudar sobre injúrias mecânicas ocorridas em sementes de feijão Vigna durante a colheita e etapas posteriores, até $\mathrm{o}$ armazenamento.

Ademais, em relação aos danos visíveis representados por rachaduras, quebras e sementes fragmentadas, as sementes danificadas podem sofrer reduções na germinação e vigor, logo depois da incidência do dano (efeito imediato) ou posteriormente (efeito latente) ao longo da armazenagem (Vieira, 1991). Por estas razões e pelo fato da cultura ser de grande potencial para o Brasil, notadamente para a região Nordeste, propõe-se, com este trabalho, investigar os impactos mecânicos sofridos pelas sementes de duas variedades de feijão Vigna (Rabo de Tatu e Cedinha) com dois teores de umidade (13,5 e 7,3\%) ao passarem pelas operações impostas depois da colheita e debulha, pelas etapas de pré-limpeza, limpeza, separação e classificação na UBS de Alagoinha, PB, a que são submetidas dentro do programa de beneficiamento de sementes desta região.

\section{MATERIAL E MÉTODOS}

O trabalho foi conduzido no Laboratório de Armazenamento e Processamento de Produtos Agrícola (LAPPA) do Departamento de Engenharia Agrícola (DEAg) da Universidade Federal de Campina Grande (UFCG), PB, e na Unidade de Beneficiamento de Sementes (UBS) da Empresa Estadual de Pesquisa Agropecuária do Estado da Paraíba (EMEPA-PB) localizada no município de Alagoinha, PB.

Foram utilizadas duas variedades de sementes de feijão macassar (Vigna unguiculata L., Walp.) denominadas Cedinha e Rabo de Tatu, com dois teores de umidade (13,5 e 7,3\%), adquiridas de agricultores idôneos, por meio da EMEPA Alagoinha, da safra 2001/2002, colhidas manualmente.

Antes do início dos trabalhos, as sementes das duas variedades foram submetidas à mesa de gravidade para uma classificação, utilizando-se, no estudo, as sementes retidas nas duas primeiras cavidades da mesa, denominadas bicas coletoras.

Depois da classificação das sementes na mesa de gravidade, formaram-se dois lotes de cada variedade, com aproximadamente $220 \mathrm{~kg}$ cada lote, os quais foram submetidos às operações da UBS, obedecendo ao esquema operacional da Figura 1 quando, após cada passagem (operação) foram coletados $6 \mathrm{~kg}$ de sementes, de onde se retirou $1 \mathrm{~kg}$ para a formação da amostra de trabalho, de cada variedade (Cedinha e Rabo de Tatu) com 13,5 e 7,3\% de umidade e de cada ponto coletado. A infestação inicial foi feita mediante observações 
visuais de uma amostra de $200 \mathrm{~g}$ de sementes e pelo teste de germinação realizado em laboratório.

Com relação a umidade, as sementes de feijão foram colhidas com $13,5 \%$, sendo que a outra metade do material colhido no campo foi submetida a secagem natural, seguindo o método de secagem adotado por Herart et al. (1981) para alcançar o teor de umidade de 7,3\%. Logo após a formação das amostras, as subamostras de $1 \mathrm{~kg}$ foram retiradas para as identificações e avaliações de danos mecânicos.
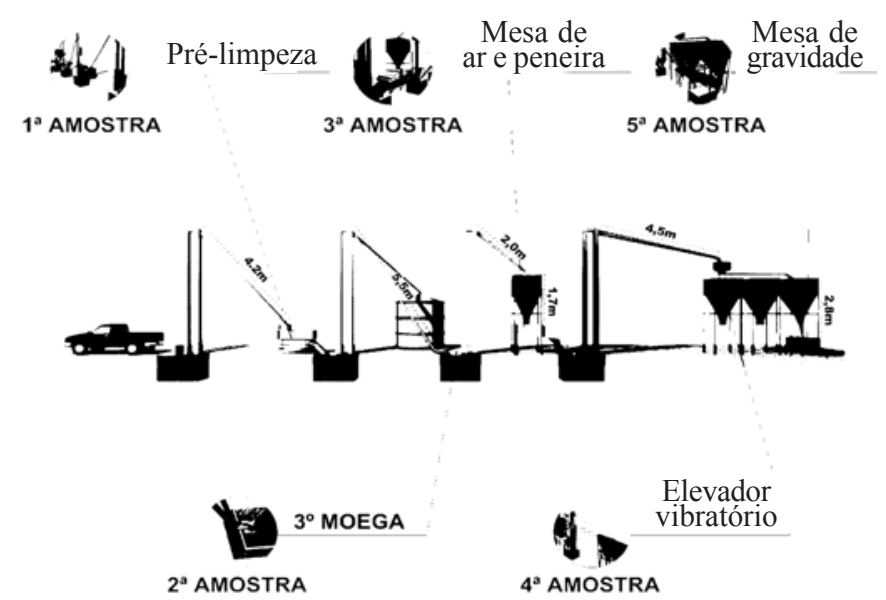

Figura 1. Esquema operacional do beneficiamento das sementes de feijão na UBS

\section{Análise de pureza física}

Para determinação da pureza física das sementes, os testes foram realizados de acordo com as Regras para Análise de Sementes (Brasil, 1992) exceto a quantidade de sementes padrão utilizadas e, para o cálculo das impurezas, pesaram-se todas as partículas presentes na amostra e as sementes defeituosas, fragmentos, sementes de outras espécies, detritos vegetais e corpos estranhos de qualquer natureza, não oriundos da cultivar considerada, retidos na quarta bica coletora da mesa de gravidade da UBS onde as sementes foram beneficiadas. A percentagem de pureza (Eq. 1) foi determinada pela relação entre a massa das sementes puras e a massa inicial da amostra, mediante o modelo matemático.

$$
\mathrm{Pf}=100 \quad 1 \quad \frac{\mathrm{Mi}}{\mathrm{Mm}}
$$

em que:

Pf - pureza física de sementes, $\%$

$\mathrm{M}_{i}$ - massa de impureza e material estranho, $\mathrm{g}$

$\mathrm{M}_{m}$ - massa inicial da amostra, $\mathrm{g}$

\section{Umidade}

Foi determinada de acordo com as recomendações das Regras para Análise de Sementes (Brasil, 1992), utilizando-se do método da estufa a $105 \pm 3{ }^{\circ} \mathrm{C}$, durante $24 \mathrm{~h}$, com duas repetições de $20 \mathrm{~g}$ cada uma.

Obteve-se a redução da umidade do segundo lote de sementes de feijão espalhando-se as sementes sobre uma lona, para secagem ao sol, sendo constantemente revolvidas e pesadas várias amostras de $10 \mathrm{~kg}$ de sementes, visando alcançar a umidade de 7,3\%, conforme o modelo matemático estabelecido por Herart et al. (1981) mostrado na Eq. 2.

$$
\mathrm{W}_{2}=\frac{100-\mathrm{A}}{100-\mathrm{B}} \cdot \mathrm{W}_{1}
$$

em que:

A - teor de umidade inicial, $\%$

B - teor de umidade desejada, $\%$

$\mathrm{W}_{1}$ - peso inicial da amostra, $\mathrm{kg}$

$\mathrm{W}_{2}$ - peso final da amostra, $\mathrm{kg}$

\section{Danos mecânicos}

Logo depois da passagem da amostra em cada etapa do beneficiamento, os danos foram avaliados visualmente, utilizando-se uma amostra de $800 \mathrm{~g}$, distribuídos em quatro repetições de $200 \mathrm{~g}$ cada uma; para isto utilizou-se uma bancada com fundo branco em razão de promover melhor identificação, conforme recomendam Andrade et al. (1999). Os danos mecânicos foram classificados nos três segmentos:

1. Danos Leves: sementes com tegumento visualmente rompido ou com fissuras

2. Danos Intermediários: sementes partidas, apresentando partes inteiras, cada uma das quais maior que a metade

3. Danos Severos: sementes partidas ao meio

Depois da separação e conforme o dano e da pesagem das sementes para cada tipo de dano, calculou-se o índice de danos mediante a expressão (Eq. 3) recomendada por Souza et al. (2002).

$$
\mathrm{D}=100 \quad \frac{\mathrm{Md}}{\mathrm{Mm}}
$$

em que:

D - índice de danos mecânicos, \%

$\mathrm{M}_{d}$ - massa de sementes com danos mecânicos, $\mathrm{g}$

$\mathrm{M}_{m}$ - massa inicial da amostra, $\mathrm{g}$

\section{Delineamento estatístico}

A análise inicial dos experimentos dos danos sofridos pelas sementes foi feita no esquema fatorial $2 \times 2 \times 5$, ou seja dois níveis de umidade (13,5 e 7,3\% b.u.) duas variedades (Cedinha e Rabo de Tatu) e cinco impactos acumulativos $\left(\mathrm{I}_{1}, \mathrm{I}_{2}, \mathrm{I}_{3}, \mathrm{I}_{4}, \mathrm{I}_{5}\right)$ em um delineamento inteiramente casualizado, com quatro repetições. Fez-se a comparação entre as médias de tratamentos utilizando-se o teste de Tukey a 1 e $5 \%$ de probabilidade, mediante o emprego do software Assistat Versão 6.5 beta (Silva, 1996).

\section{RESULTADOS E DISCUSSÃO}

\section{Pureza física}

Os dados aqui comentados não sofreram análise estatística, pois não houve repetições para os tratamentos, mas foram calculados como porcentagem de peso total das sementes antes que estas fossem submetidas às cinco etapas do 
beneficiamento na Unidade de Beneficiamento de Sementes (UBS) e sofressem impactos consideráveis. Os dados dos resultados de caracterização do feijão Vigna, contidos na Tabela 1, revelaram, para esse fator, para as sementes das variedades Cedinha e Rabo de Tatu colhidas manualmente, 95,84 e 95,42\% de pureza, respectivamente; foram contabilizadas como impurezas, fragmentos de sementes, pedaços de tegumento, frações de plantas, partículas de solo e areia, resultantes da batedura manual, cujos resultados reforçam os encontrados por Souza et al. (2002), que verificaram elevada porcentagem de pureza para as sementes de feijão colhidas manualmente com teor de umidade próximo de $13,5 \%$.

Tabela 1. Resultados médios (\%) de pureza física, teor de umidade e infestação em sementes de duas variedades de feijão Vigna, colhidas e debulhadas por batedura manual

\begin{tabular}{cccc}
\hline Variedade & Pureza Física & $\begin{array}{c}\text { Teor de } \\
\text { Umidade }\end{array}$ & $\begin{array}{c}\text { Semente } \\
\text { Infestada }\end{array}$ \\
\hline Cedinha & 95,84 & 13,5 & 0 \\
Rabo de Tatu & 95,42 & 13,5 & 0 \\
\hline Média & 95,63 & 13,5 & 0 \\
\hline
\end{tabular}

Constata-se, nos resultados da Tabela 1, uniformidade das variedades em relação ao grau de umidade e ausência de infestação por insetos. Esta ausência de infestação se deve, provavelmente, à época de colheita e às condições ambientais da região. Smith \& Berjak (1995) relatam que as infestações e, ou infecções por insetos e microrganismos estão diretamente relacionadas com as condições ambientais, principalmente após a maturação fisiológica das sementes.

O elevado grau de pureza se deve, provavelmente, à colheita manual, seguida da debulha por meio de batedura também manual, em que, ao contrario da debulha mecânica, as sementes não sofrem injúrias mecânicas decorrentes das forças que lhes são aplicadas, a fim de separá-las das vagens, devido às conseqüências dos impactos recebidos do cilindro debulhador e no momento em que passa através do côncavo.

\section{Avaliação dos danos mecânicos}

A análise de variância revelou valores de $\mathrm{F}$ significativos a 1 e $5 \%$ de probabilidade para impactos, variedades, umidades e suas interações, enquanto o desdobramento da análise de regressão indicou efeito linear para todos os tratamentos (Tabela 2).

A Figura 2A contém os resultados dos danos sofridos pelas sementes de feijão Vigna, obtidos experimentalmente pela avaliação visual, depois de sofrerem impacto em cada operação na UBS, durante o beneficiamento. Observa-se que a intensidade de danos se eleva com o aumento do número de passagens da semente pelas diferentes etapas da UBS, à qual estas são impostas, apresentando maior intensidade para as sementes da variedade Rabo de Tatu, exceto com relação ao impacto de número $5\left(\mathrm{I}_{5}\right)$, quando ocorreu igualdade estatística desta com a variedade Cedinha; no entanto, em termos médios a variedade Rabo de Tatu foi 14,92\% mais susceptível aos impactos impostos pela UBS, comparando-se com a variedade Cedinha, ocorrência que a diferencia, em parte, das explicações
Tabela 2. Resumo da análise de variância e de regressão para sementes danificadas de feijão Vigna pelos impactos, durante seu beneficiamento na unidade. Campina Grande, PB, 2003

\begin{tabular}{lcc} 
Fontes de Variação & G.L & $\begin{array}{c}\text { Quadrado } \\
\text { Médio }\end{array}$ \\
\hline Impactos & 4 & $29,88^{* *}$ \\
Variedade & 1 & $18,86^{* *}$ \\
Umidade & 1 & $37,96^{* *}$ \\
Impactos x Variedades & 4 & $1,38^{* *}$ \\
Impactos x Umidades & 4 & $0,34^{*}$ \\
Variedades x Umidades & 1 & $9,78^{* *}$ \\
Impactos x Variedadesx Umidade & 4 & $1,30^{* *}$ \\
Danos da Variedade Cedinha $(13,5 \%$ bu) & & \\
Linear & 1 & $23,97^{* *}$ \\
Danos da Variedade Cedinha (7,3\% bu) & & \\
Linear & 1 & $67,70^{* *}$ \\
Danos da Variedade Rabo de Tatu (13,5\% bu) & & \\
Linear & 1 & $24,66^{* *}$ \\
Danos da Variedade Rabo de Tatu $(7,3 \%$ bu) & & \\
Linear & 1 & $14,10^{* *}$ \\
Resíduo & 60 & 0,09 \\
\hline CV (\%) & 3,60 \\
** Significativo a 1 e 5\% de probabilidade, respectivamente &
\end{tabular}

** Significativo a 1 e $5 \%$ de probabilidade, respectivamente

referenciadas por Kannenberg \& Allard (1964) ao concluírem, em seu estudo sobre a associação entre a pigmentação e a formação da lignina em tegumento de feijão tipo lima (Phaseolus lunatos L.), de cor branca, que apresentaram menor proteção ao embrião que as sementes de tegumento colorido e, ainda, que sementes com tegumento branco são mais facilmente danificadas; possuem tegumento mais fino; germinam mais rapidamente e são inferiores em emergência. Todavia, para esses autores a mais notável diferença entre os dois tipos de semente é o menor conteúdo de lignina no tegumento das sementes brancas; tendo em vista que a função da lignina é primariamente estrutural e protetora, concluíram, portanto, que o baixo conteúdo de lignina das sementes brancas foi à causa da sua maior susceptibilidade à danificação. As sementes da variedade Rabo de Tatu, de cor vermelha, apresentaram maior susceptibilidade aos danos provocados pelos impactos, porém se justifica essa divergência devido ao tipo de semente, que diferem em tamanho, geometria e estrutura. De acordo com Andrade et al. (1998) a posição do impacto também influencia a porcentagem de sementes danificadas, em que a região do hilo é a mais susceptível aos danos que a região oposta ao hilo.

Atkin, citado por Toledo (1971) trata do tema, informando que o tegumento da semente das variedades resistentes a impactos mecânicos, por ele estudado em 18 variedades de feijão é, geralmente, muito mais aderente ao cotilédone. Tegumento aderente e cotilédones bem unidos reduzem ou previnem a movimentação dos mesmos, protegendo o embrião contra danificações. Almeida et al. (1997) observaram que a qualidade da semente é influenciada também pela dureza e características genotípicas de cada espécie e/ou variedade, podendo segundo Carvalho \& Nakagawa (1988) influenciar a susceptibilidade à quebra, a qual se refere ao potencial de 
fragmentação do produto quando este é submetido a uma força de impacto durante o beneficiamento ou transporte (Gunasekaran \& Muthukumaratpan, 1993).

Verifica-se na Figura 2B, referente à interação entre impacto e umidade, uma diferença percentual em torno de $15,6 \%$ de quebra entre as sementes com umidade de 7,3 e 13,5\%. Quando da passagem das sementes pelas diferentes etapas da UBS, verificou-se que a umidade é um fator a ser considerado antes do seu beneficiamento.

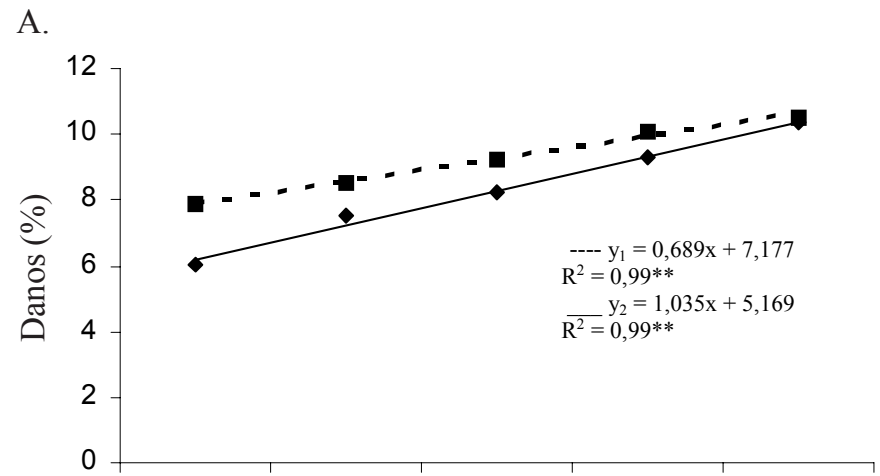

B.

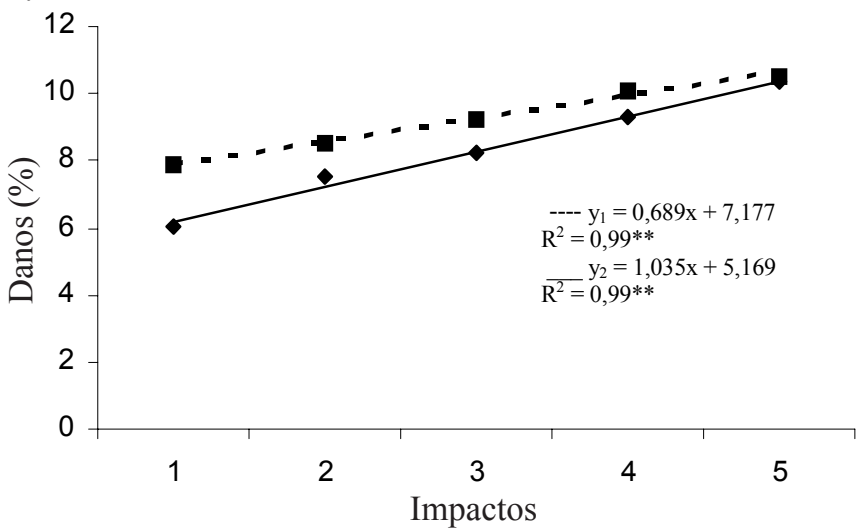

Figura 2. Estimativa dos danos sofridos pelas sementes da variedade (A) Rabo de Tatu ( $\mathrm{y}_{1}$ ) e Cedinha ( $\mathrm{y}_{2}$ ) e umidade (B) durante o processo de beneficiamento na unidade de Alagoinha. Campina Grande, PB, 2003

De acordo com Almeida et al. (1997) o conhecimento do teor de umidade das sementes é essencial para se determinar às condições adequadas para o correto beneficiamento. A variedade Rabo de Tatu foi mais susceptível a danificações, evidenciando o efeito da umidade nas sementes, quando a sua umidade é reduzida de 13,5 para 7,3\%. Evans et al. (1990) trabalhando com danos mecânicos em leguminosas, como soja, por exemplo, concluíram também que o grau de umidade e a velocidade de impacto são fatores importantes que definem a intensidade das injúrias mecânicas nas sementes.

Analisando-se os dados da interação variedade $\mathrm{x}$ umidade (Tabela 3) verifica-se que o número de sementes danificadas aumentou com a diminuição do grau de umidade. As maiores percentagens de sementes danificadas foram obtidas para as sementes impactadas com $7,3 \%$ de umidade, valor que representa, em média, 1,38 ponto percentual a mais que as sementes impactadas na UBS, com $13,5 \%$ de umidade, o que corresponde a $17,12 \%$ de susceptibilidade daquelas frente a essas. Ademais, tem-se efeito positivo para variedade, onde a Rabo de Tatu foi menos resistente aos impactos que a Cedinha. Verifica-se, assim, que sementes com umidade mais elevada possuem maior capacidade para absorver os impactos, resultando numa integridade melhor de suas partes físicas e que esta é influenciada também pelas características da variedade, conforme já observado por outros autores, entre os quais Almeida et al. (1997) e Gunasekaran \& Muthukumaratpan (1993).

Tabela 3. Valores médios (\%) de sementes danificadas de feijão Vigna das variedades Cedinha e Rabo de Tatu pelos impactos sofridos nos diferentes pontos de coletas na UBS durante o beneficiamento, para a interação Variedade x Umidade. Campina Grande, PB, 2003*

\begin{tabular}{ccc}
\hline \multirow{2}{*}{ Umidade (\%) } & \multicolumn{2}{c}{ Variedade } \\
\cline { 2 - 3 } & Cedinha & Rabo de Tatu \\
\hline 13,5 & $7,23 \mathrm{bB}$ & $8,90 \mathrm{bA}$ \\
$7 ., 3$ & $9,31 \mathrm{aA}$ & $9,58 \mathrm{aA}$ \\
\hline \multirow{2}{*}{ DMS (Tukey a 1\%) } & Entre variedade & 0,20 \\
CV\% & Entre umidade & 0,20 \\
& & 3,60 \\
\hline
\end{tabular}

" Comparação de médias seguidas de letras maiúsculas nas linhas e minúsculas nas colunas não diferem pelo teste de Tukey a $5 \%$

Carvalho (1969) utilizando sementes de feijão macassar (Vigna sinensis L.), estudou os efeitos imediatos das injúrias mecânicas em algumas características fisiológicas das sementes. Analisando os impactos causados por quedas livres sobre uma placa de metal, viram que os efeitos imediatos das injúrias dependiam da altura de queda e da umidade das sementes, e que os danos foram proporcionais à altura de queda, porém com o aumento da umidade das sementes, pode-se reduzir bastante os danos causados pelos impactos.

Merch \& Gomes (1982) recomendaram estabelecer teores de umidade ideais para o beneficiamento e o próprio armazenamento de cada espécie ou variedade de sementes, admitindo-se que esses teores podem ser específicos a cada região.

Salienta-se ainda que as sementes da variedade Rabo de Tatu são mais graúdas, a pigmentação do seu tegumento é vermelha, enquadrando-se nas observações de Abrahão (1971) quando afirmou que as sementes graúdas, de tegumento relativamente delicado e de embrião ocupando posição mais superficial, são mais sensíveis a quebras ou injúrias mecânicas.

\section{CONCLUSÕES}

1. As injúrias mecânicas impostas pela passagem das sementes nas diferentes etapas da Unidade de Beneficiamento de Sementes constituíram-se em importante fator de depreciação da qualidade das sementes.

2. As injúrias se elevam com o aumento do número de passagem das sementes pelas diferentes etapas da Unidade de Beneficiamento de Sementes à qual estão sujeitas, demonstrando caráter cumulativo, indicando haver uma relação direta entre o número de choques e seus efeitos. 
3. A variedade Rabo de Tatu mostrou-se mais sensível que a variedade Cedinha referente aos efeitos dos impactos impostos nas diferentes etapas a que foram submetidas durante o beneficiamento.

4. Sementes beneficiadas, com teor de umidade de 7,3\% b.u. são mais susceptíveis à quebra ocasionada pelos impactos que as sementes beneficiadas com $13,5 \%$.

\section{LITERATURA CITADA}

Abrahão, J.T.M. Contribuição do estudo de efeito de danificações mecânicas em sementes de feijão. Piracicaba: ESALQ, 1971.112p. Tese Doutorado

Almeida, F.A.C.; Hara, T.; Cavalcanti Mata, M.E.R.M. Armazenamento de grãos e sementes nas propriedades rurais. 1.ed. Campina Grande: UFPB/SBEA, 1997. 291p.

Andrade, E.T.; Corrêa, P.C.; Alvarenga, E.M.; Martins, J.H. Efeitos de danos mecânicos controlados sobre a qualidade fisiológica de sementes de feijão durante o armazenamento. Revista Brasileira de Armazenamento, Viçosa, v.23, n.2, p.4151, 1998.

Andrade, E.T.; Corrêa, P.C.; Alvarenga, E.M.; Martins, J.H. Efeito do impacto mecânico controlado sobre a qualidade fisiológica de sementes de feijão. Engenharia na Agricultura, Viçosa, v.7, n.3, p.148-159, 1999.

Brasil. Ministério da Agricultura e Reforma Agrária. Regras para análise de sementes. Brasília DF, 1992.365p.

Carvalho, N.M. Some phisiological responses of cow-pea seed (Vigna sinensis) to mechanical injury. State College: Mississippi State University. 1969. 84p. M.S. Thesis

Carvalho, N.M.; Nakagawa, J. Injúria mecânica: Sementes, Ciência, Tecnologia e Produção. 3. ed. Campinas: Fundação Cargill, 1988.424p.

CONAB - Companhia Nacional de Abastecimento. Produção agrícola brasileira. www.agricultura.gov.br/spa/anuario. 15 jan. 2003.

Evans, M.D.; Holmes, R.G.; McDonald, M.B. Impact damage to soybean seed as affected by surface hardness and seed orientation. Transactions of the ASAE, St. Joseph, v.33, n.1, p.234-240, 1990.
Gunasekaran, S.; Muthukumaratpan, K. Breakage susceptibility of corn of different stress-crock categories. Transactions of the ASAE, St. Joseph, v.36, n.5, p.1445-1446, 1993.

Herart, H.B.; Don, R.; Jack, D.A. Investigation in the effect of damage caused by mechanical treatment of muny bean (Vigna radiate) seed at various seed moisture level. Seed, Science and Technology, Zurich, v.9, p.853-860, 1981.

Kannenberg, J.W.; Allard, R.W. An association between pigment and lignin formation in the seed coat of the Lima bean. Crop Science, Madison, n.4, p.621-622, 1964.

Martins Netto, D.A.; Borba, C.S.; Oliveira, A.C.; Azevedo, J.T.; Andrade, R.V. Efeito de diferentes graus de dano mecânico na qualidade fisiológica de sementes de sorgo. Revista da Pesquisa Agropecuária Brasileira, Brasília, v.34, n.8, p.1475$1480,1999$.

Merch, R.; Gomes, N.P. Beneficiamento e armazenamento de grãos. Porto Alegre: CESA, 1982. 104p.

Papes, A.C. Produção de feijão $350 \%$ maior que a registrada na Paraíba no ano de 2001. Jornal da Paraíba, Campina Grande, PB, 18 de dezembro de 2002. Caderno Economia, p.5.

Silva, F.A.S. The Assistat Software: statistical assistence. In: International Conference on Computers in Agriculture, 1996, Cancun. Anais... Cancun: American Society of Agricultural Engineers, 1996. p.294-298.

Smith, M.T.; Berjak, P. Deteriorative changes associated with the loss of viability of stored desiccations of seed associated Mycoflora during storage. In: Jaime, K.; Galili, G. Seed development and germination. New York : Marcel Dekker Inc, 1995. p.701-746.

Souza, C.M.A.; Queiroz, D.M.; Mantovani, E.C.; Cecon, P.R. Efeito da colheita mecanizada sobre a qualidade de sementes de feijão (Phaseolus vulgaris L.). Revista Brasileira de Armazenamento, Viçosa, v.27, n.1, p.21-29, 2002.

Toledo, F.F. Contribuição ao estudo de efeitos de danificação mecânica em sementes de feijoeiro (Phaseolus vulgaris L.). Piracicaba: ESALQ, 1971. 111p. Tese Doutorado.

Vieira, E.R. Comparação entre métodos para avaliação da qualidade fisiológica de sementes de feijão (Phaseolus vulgaris L.). Lavras: Universidade Federal de Lavras. 1991. 87p. Dissertação Mestrado

Yokoyama, L.P.; Wetzel, C.T.; Vieira, E.H.N.; Pereira, G.V. Sementes de feijão: produção, uso e comercialização. In: Vieira, E.H.N.; Rava, C.A. In: Sementes de feijão: produção e tecnologia. Santo Antônio de Goiás: EMBRAPA Arroz e feijão, 2000. cap.12, p.249-270. 